\title{
Optimal Feed Profile for a Second Order Reaction in a Semi-Batch Reactor under Safety Constraints.
}

\section{Experimental Study}

\author{
O. Ubrich ${ }^{+}$, B. Srinivasan*, D. Bonvin*, F. Stoessel ${ }^{+}$ \\ ${ }^{+}$Institut de Génie Chimique, Ecole Polytechnique Fédérale de Lausanne \\ * Institut d'Automatique, Ecole Polytechnique Fédérale de Lausanne
}

CH-1015 Lausanne, Switzerland

\begin{abstract}
Maximising the yield of the second order reaction (2-butanol + propionic anhydride) by manipulating the inlet flow rate is considered for an isothermal semi-batch process. First a procedure for the determination of the kinetic parameters using coupled spectroscopic and calorimetric methods is presented. Then an optimisation of the considered reaction is performed numerically and verified experimentally. Constraints on the amount of heat produced and on the temperature attainable in case of a cooling failure are imposed for safety consideration.
\end{abstract}

\section{Keywords}

Kinetic parameters determination, Semi-batch reaction system, Safety constraints, Optimisation.

\section{Introduction}

Semi-batch reactor operation is very common in the speciality chemicals industry. The goal of any chemical industry is to maximise the productivity on using stable and safe processes. Since most of the reactions are exothermic, in case of a cooling failure and if no preventive measures were taken, a runaway situation with severe consequences may develop (Rogers 1997).

In a previous work (Ubrich et al. 1999), a feed strategy was developed which allows to optimize the productivity under safety constraints. This optimal addition profile can be implemented by using a control loop with feed-back. The present paper focuses on the off-line determination of an optimum addition profile and its implementation in an open-loop.

For an off-line optimization, it is obvious that a mathematical model basing on precise kinetic data of the reaction is required. These parameters can be estimated with the help of calorimetric methods (Snee \& al. 1993, Leonhardt \& al. 1997) or basing on spectroscopic measurements (Holzwarth 1996). For an exhaustive list of all the articles published on kinetic determination in Chemical Abstracts between October 1995 and October 1997, see Crouch (1998). However, most of the time, both methods are dissociated and complex mathematical tools are used.

For the determination of the kinetic parameters of a second order reaction, a simple method witch couples spectroscopic (Raman and infra-red) and calorimetric methods running simultaneously, is proposed here.

Once the kinetic parameters have been determined, the conditions allowing a maximum conversion for an isothermal semi-batch process can be defined. The optimisation respects the imposed safety constraints. In this way, the system stays stable as well under normal operating conditions as in the case of a cooling failure. It also maximises the productivity i.e. minimises the time required to achieved a given conversion.

Section 2 formulates the problem, while Section 3 deals with identification of thermokinetic parameters. In Section 4, the optimal solution is verified experimentally.

\section{Theory and model}

\subsection{Chemical reaction}

As a model reaction, the exothermic esterification propionic anhydride with 2-butanol working in a semi-batch reactor in the isothermal mode is considered:

The reaction is:<smiles>CCCCCC(C)O[C@H](O)CCC(=O)OC(=O)CC</smiles>

In the following article, this reaction will be symbolised as:

$$
\mathrm{A}+\mathrm{B} \rightarrow \mathrm{C}+\mathrm{D}
$$

This reaction is known to be a second order reaction (Strozzi \& al. 1997) i.e. first order for each reactant.

\subsection{Problem formulation}

The reactor is initially charged with $A\left(N_{A, 0}\right.$ moles and volume $\mathrm{V}_{\mathrm{A}, 0}$ ). Species $\mathrm{B}$ of concentration 
$\mathrm{N}_{\mathrm{B}, 0} / \mathrm{V}_{\mathrm{B}, 0}$ is fed through the inlet with a volumetric flow rate $u$.

Molar balances give the following expressions for $\mathrm{N}_{\mathrm{A}}$ and $\mathrm{N}_{\mathrm{B}}$, the number of moles of $\mathrm{A}$ and $\mathrm{B}$ :

$$
\begin{aligned}
& \mathrm{N}_{\mathrm{A}}=\mathrm{N}_{\mathrm{A}, 0}\left(1 \square \mathrm{x}_{\mathrm{A}}\right) \\
& \mathrm{N}_{\mathrm{B}}=\mathrm{N}_{\mathrm{B}, 0} \frac{\mathrm{V} \square \mathrm{V}_{\mathrm{A}, 0}}{\mathrm{~V}_{\mathrm{B}, 0}} \square \mathrm{N}_{\mathrm{A}, 0} \mathrm{x}_{\mathrm{A}}
\end{aligned}
$$

where $\mathrm{x}_{\mathrm{A}}$ is the molar conversion of $\mathrm{A}, \mathrm{V}$ the actual volume of the reaction mass.

The optimal control problem consists of minimising the remaining number of moles of the reactants for a given final time $\left(t_{f}\right)$ by adapting the feed flow rate $\mathrm{u}$.

$$
\min _{\mathrm{u}(\mathrm{t})} \mathbf{J}=\mathrm{N}_{\mathrm{A}}\left(\mathrm{t}_{\mathrm{f}}\right)
$$

From molar and mass balances, the system equation reads:

$$
\begin{array}{lr}
\dot{\mathrm{x}}_{\mathrm{A}}=\frac{\mathrm{r} \mathrm{V}}{\mathrm{N}_{\mathrm{A}, 0}} & \mathrm{x}_{\mathrm{A}}(0)=0 \\
\dot{\mathrm{V}}=\mathrm{u} & \mathrm{V}(0)=\mathrm{V}_{\mathrm{A}, 0}
\end{array}
$$

where $\mathrm{r}$ is the reaction rate and can be defined as:

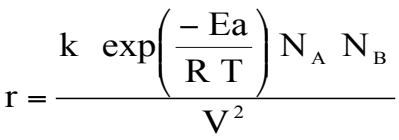

where $\mathrm{Ea}$ is the activation energy, $\mathrm{T}$ the temperature, $\mathrm{R}$ the gas constant and $\mathrm{k}^{\circ}$ the frequency factor of the rate constant.

The constraints of this optimisation problem are:

- the physical limitation of the volume.

$$
\mathrm{V} \square \mathrm{V}_{\max }=\mathrm{V}_{\mathrm{A}, 0}+\mathrm{V}_{\mathrm{B}, 0}
$$

- the physical limitation of feed rate.

$$
\mathrm{u}_{\min } \square \mathrm{u} \square \mathrm{u}_{\max }
$$

- the cooling capacity of the reactor.

$$
\mathrm{q}_{\mathrm{rx}}=\mathrm{r}\left(\square \square \mathrm{H}_{\mathrm{r}}\right) \mathrm{V} \square \mathrm{q}_{\mathrm{ex}}=\mathrm{UA}\left(\mathrm{T} \square \mathrm{T}_{\mathrm{c}}\right)
$$

where $\mathrm{q}_{\mathrm{rx}}$ is the heat produced by the chemical reaction and $\mathrm{q}_{\mathrm{ex}}$ the maximal heat released. $\square \mathrm{H}_{\mathrm{r}}$ is the molar enthalpy of the reaction. $\mathrm{U}, \mathrm{A}$ and $\mathrm{T}_{\mathrm{c}}$ symbolise the overall heat transfer coefficient, the heat exchange area and the temperature of the coolant respectively.
In order to stay in an isothermal mode, the cooling system has to be able to remove the heat produced by the chemical reaction.

- the accumulation of non converted reactant expressed as the maximum temperature which can be reached in case of a cooling failure.

$\mathrm{T}_{\mathrm{cf}}=\mathrm{T}+\min \left(\mathrm{N}_{\mathrm{A}}, \mathrm{N}_{\mathrm{B}}\right) \frac{\left(\square \square \mathrm{H}_{\mathrm{r}}\right)}{\square \mathrm{c}_{\mathrm{p}} \mathrm{V}} \square \mathrm{T}_{\text {max }}$

where $\square$ is the specific weight, $c_{p}$ the specific heat capacity, $\mathrm{u}_{\min }$ and $\mathrm{u}_{\max }$ the input bounds and $\mathrm{T}_{\max }$ the bound temperature.

$\mathrm{T}_{\text {cf }}$ represents the maximum temperature the reaction mass can reach in case of a cooling failure (Lerena \& al. 1996). Indeed, in case of a cooling failure, the system can be considered to be adiabatic. Due to the presence of non-reacted components in the reactor, the reaction is still active. Therefore, some heat will be released even if the feed has been immediately stopped and lead to an increase of the reaction mass temperature (Hugo \& al. 1988)

The constraint (8) deals with normal operation. It imposes the system to produce less heat than can be removed. The constraint (9) deals with cooling failure. It imposes the reached temperature in case of a cooling failure to be inferior to an imposed temperature.

\subsection{Characterisation of the solution}

At any time, the input can take one of the four values (Ubrich \& al. 1999):

- Input at its maximum: $\mathrm{u}=\mathrm{u}_{\max }$

- Input determined by the heat removal (8): $\mathrm{u}=\mathrm{u}_{\mathrm{c} 1}$

- Input determined by $\mathrm{T}_{\mathrm{cf}}(9): \mathrm{u}=\mathrm{u}_{\mathrm{c} 2}$

- Input at its minimum: $\mathrm{u}=\mathrm{u}_{\min }$

$\mathrm{u}_{\mathrm{c} 1}$ and $\mathrm{u}_{\mathrm{c} 2}$ can be calculated from $\mathrm{d}\left(\mathrm{q}_{\mathrm{rx}}-\mathrm{q}_{\mathrm{ex}}\right) / \mathrm{dt}=0$ and $\mathrm{d}\left(\mathrm{T}_{\mathrm{cf}}\right) / \mathrm{dt}=0$ respectively.

The switching times between the different modes of expression of the input depend on which constraint is governing the system.

$$
\begin{aligned}
& \mathrm{u}_{\mathrm{c} 1}=\frac{\mathrm{r} \mathrm{V}^{2}\left(\mathrm{~N}_{\mathrm{A}}+\mathrm{N}_{\mathrm{B}}\right)}{\mathrm{N}_{\mathrm{A}} \mathrm{O}_{\mathrm{B}, \mathrm{N} \mathrm{N}_{\mathrm{B}, 0} \mathrm{~V}}^{\mathrm{V}_{\mathrm{B}}} \square \mathrm{N}_{\mathrm{B}} \text { 貝 } \square \frac{2 \mathrm{~V}^{2} \mathrm{U}\left(\mathrm{T} \square \mathrm{T}_{\mathrm{c}}\right)}{\mathrm{d}_{\mathrm{r}} \mathrm{k}\left(\square \square \mathrm{H}_{\mathrm{r}}\right)}} \\
& u_{c 2}=\frac{k^{\circ} \exp \text { 目 }^{\mathrm{E} T} \mathrm{~T} \text { 目 } \mathrm{N}_{\mathrm{A}} \mathrm{N}_{\mathrm{B}}}{\frac{\mathrm{N}_{\mathrm{B}, 0} \mathrm{~V}_{\mathrm{A}, 0}}{\mathrm{~V}_{\mathrm{B}, 0}}+\mathrm{N}_{\mathrm{A}, 0} \mathrm{x}_{\mathrm{A}}}
\end{aligned}
$$




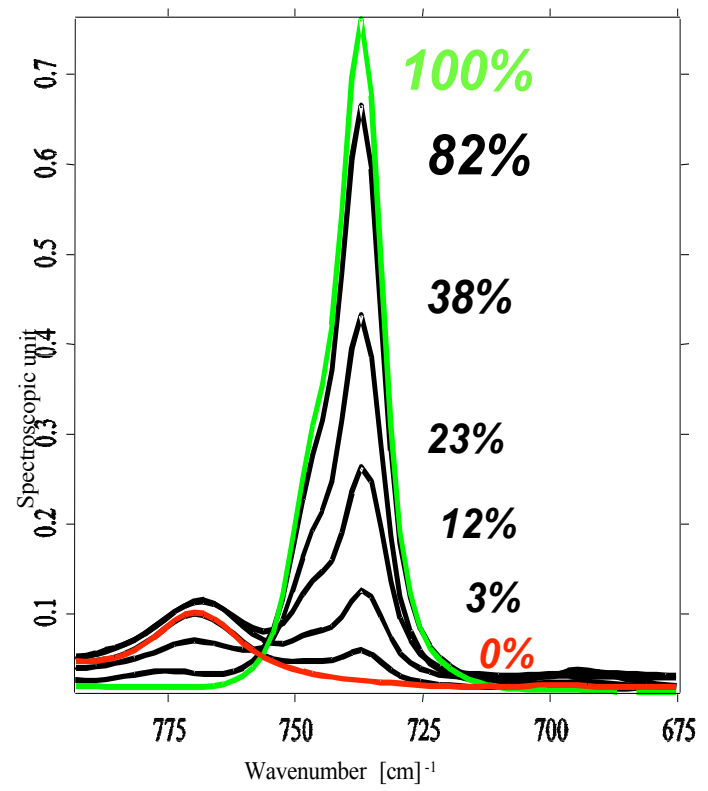

Variation of the intensity with the concentration .

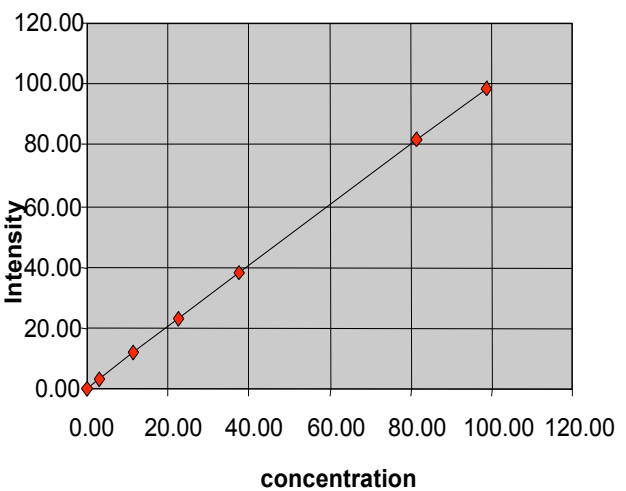

Fig. 1 Calibration of spectroscopic spectra

where $d_{r}$ is the radius of the reactor and $k$ the kinetic rate constant.

The feed rate is a function of both actual reaction rate and conversion. This means that differential (reaction rate) and integral ( conversion) variables are required for this computation. For this reasons, it was decided to use a coupled approach for the kinetic study. The differential measurement is provided by the calorimetry and the integral by the spectroscopic measurements.

\section{Kinetic parameters identification}

In order to be able to establish the optimal conditions for the esterification, the first step is to identify the kinetic parameters. For that aim, the reaction was performed in the batch mode at different temperatures in a calorimeter $\mathrm{RC} 1 \square$ (1995) equipped with two spectroscopic probes: Raman (Drago 1977) and infra-red (Hesse \& al. 1997). The RC1 allows to measure the heat of the reaction and the thermal conversion. Here the thermal conversion is equal to the molar conversion because a simple reaction is considered. In the same time, the spectroscopic probes gives some spectra of the reaction. These can be transformed into molar conversion. Then, a fitting of the results will be performed with Scientist $\square$ (1995) in order to identify the kinetic parameters allowing to build a mathematical model (Maria \& al. 1998).

\subsection{Results from the Raman spectroscopy}

The experiments have been performed at 65, 70 and $75^{\circ} \mathrm{C}$. Spectra of the reaction were taken every 5 minutes during a period of 6 hours. The Raman spectra need to be calibrated in order to determine the molar conversion (Chalmers 1997).

The calibration uses the following assumption:

The concentration of a product is proportional to the area of a peak (See Figure 1).
A fitting of the experimental data using the second order model (eq. 2) is performed with Scientist and gives the results proposed in the Figure 2.

The kinetic parameters were chosen in order to fit the model. The statistical correlation coefficients $\mathrm{R}$ was found larger than 0,9991 .

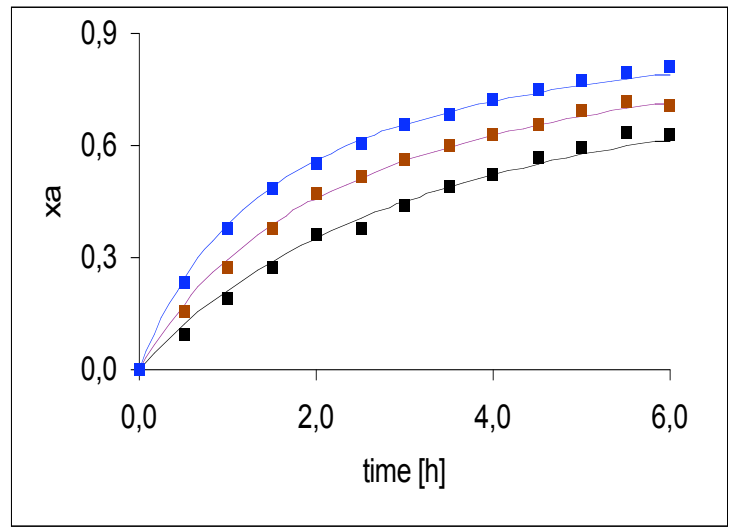

Fig.2 Simulated (solid line) and experimental Raman values $(\boldsymbol{\square})$ of the esterification reaction for a temperature of the reaction mass of $65,70,75^{\circ} \mathrm{C}$.

\subsection{Results from the infra-red_spectroscopy}

The experimental conditions are the same as above. Spectra of the reaction were taken every 10 minutes during a period of 6 hours. The infra-red spectra need also to be calibrated in order to determine the molar conversion (Chalmers 1997). The calibration is done in the same way than with Raman.

A fitting of the experimental data using the second order model (eq. 2) gives the results proposed in the Figure 3.

The kinetic parameters were chosen in order to fit the model. The statistical correlation coefficients $\mathrm{R}$ was found larger than 0,9997 . 


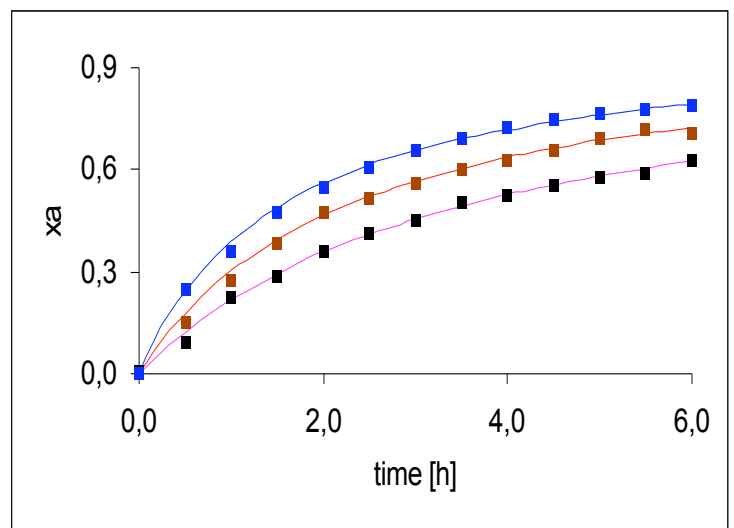

Fig.3 Simulated (solid line) and experimental infrared values $(\boldsymbol{\square})$ of the esterification reaction for a temperature of the reaction mass of $65,70,75^{\circ} \mathrm{C}$.

\subsection{Results from $R C 1$}

Since the methods were coupled, the experiment conditions are the same as above.

\subsubsection{Evaluation of the heat of reaction}

The enthalpy of the reaction determined by a direct integration of the signal without any correction at $70^{\circ} \mathrm{C}$ is (see Figure 4):

$$
\text { Qr }=-52.5 \mathrm{~kJ} / \mathrm{mol} \text {. }
$$

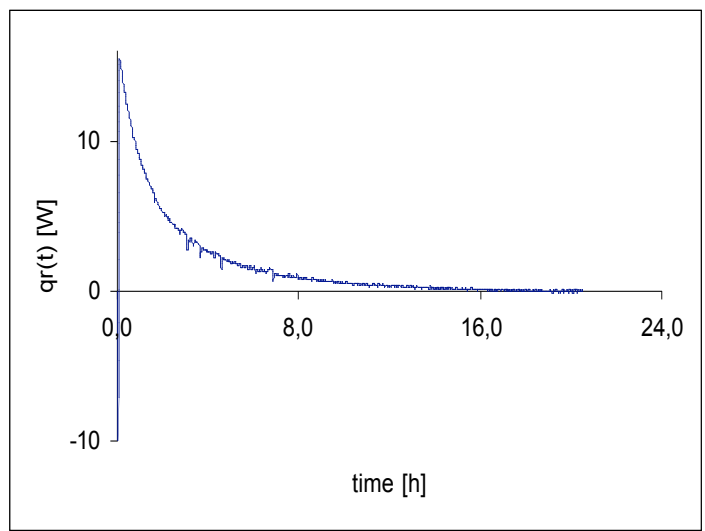

Fig.4 Evolution of the heat of the esterification reaction at $70^{\circ} \mathrm{C}$ given by the $\mathrm{RC} 1$

However, this result does not represent the real heat of the reaction. This is for two reasons:

- when the alcohol, heated previously at the experiment temperature is added to the anhydride, there is a significant drop in the temperature of the reaction mass, which is due to the endothermic heat of mixing.

- the thermal signal approaches the base-line after approx. 20 hours. But as spectroscopic measurements show, the reaction is not completed at this time. This is a very general problem for second order reactions especially when they are slow as in our example. The thermal signal approaches the base line asymptotically rending the determination of the end of the reaction difficult.

So, the measured heat released rate curve must be corrected (Regenass 1997). For this the reaction has been performed in a Calvet calorimeter Setaram C800 (1996) in order to evaluate the mixing energy (see Figure 5).

$$
\square \mathrm{H}_{\text {mix }}=-2.5 \mathrm{~kJ} / \mathrm{mol}
$$

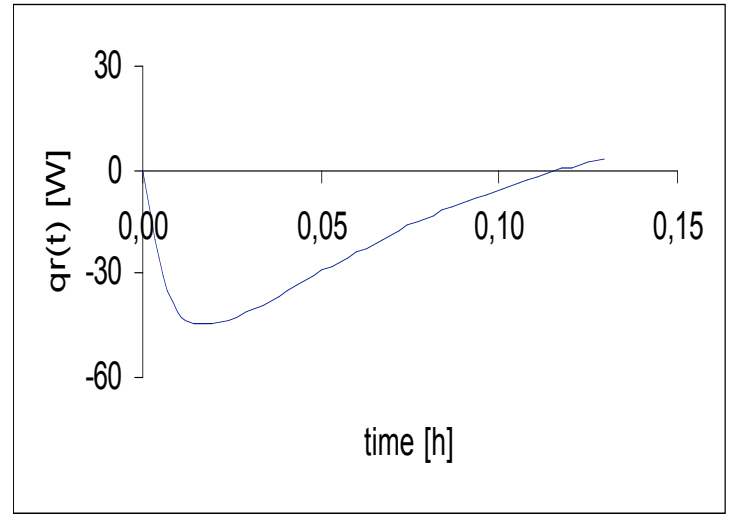

Fig. 5 Evolution of the heat of the esterification reaction at $70^{\circ} \mathrm{C}$ given by the $\mathrm{C} 80$. Zoom of the beginning of the reaction.

To determine the thermal conversion, a calibration has been performed. After 20 hours at $70^{\circ} \mathrm{C}$, the conversion is $90 \%$. Therefore, the "corrected" value of the heat of the reaction is:

$$
\square \mathrm{H}_{\mathrm{r}} \square-52.5 / 0.9-2,5 \square-61 \pm 1 \mathrm{~kJ} / \mathrm{mol}
$$

Strozzi and al. (1997) proposed $-62,99 \mathrm{~kJ} / \mathrm{mol}$ for this reaction.

The conversion at the end of the experiment has been taken into account to correct the values of the thermal conversion in order to fit the data. This shows a limitation of the calorimetric measurements. Indeed, to convert them into kinetic data, the molar conversion at the end of the experiment has to be measured by analysis.

\subsubsection{Evaluation of the kinetic constant}

If the second order model describes the chemical reaction, the thermal conversion will suit the equation (2). In order to evaluate the molar conversion, a calibration of the results was made with the help of the spectroscopic methods.

A fitting of the experiment data gives the results depicted in the Figure 6:

The kinetic parameters were chosen in order to fit the model. The statistical correlation coefficients $\mathrm{R}$ was found larger than 0,9995 . 


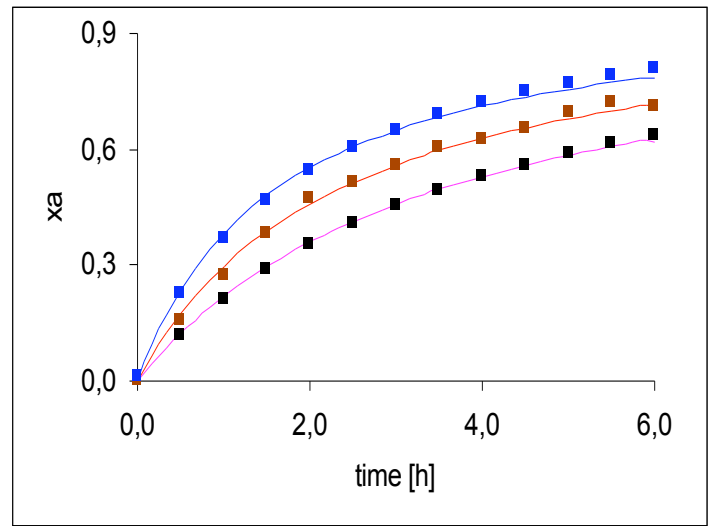

Fig.6 Simulated (solid line) and experimental RC1

values $(\boldsymbol{\square})$ of the esterification reaction for a temperature of the reaction mass of $65,70,75^{\circ} \mathrm{C}$.

3.4 Evaluation of the activation energy and of the kinetic constant

The results of the 3 experiments described are given in Table 1.

Table 1 Results obtained by spectroscopic and calorimetric methods for 65,70 and $75^{\circ} \mathrm{C}$

\begin{tabular}{|c|c|c|c|}
\hline & $\begin{array}{c}\text { Raman } \\
\text { Spectroscop } \\
\mathrm{y}\end{array}$ & $\begin{array}{c}\text { Infra red } \\
\text { Spectroscop } \\
\mathrm{y}\end{array}$ & $\begin{array}{c}\text { Calorimetry } \\
\mathrm{RC} 1\end{array}$ \\
\hline $\begin{array}{c}\mathrm{k}\left(65^{\circ} \mathrm{C}\right) \\
{[1 / \mathrm{mol} . \mathrm{h}]}\end{array}$ & 0.060 & 0.060 & 0.062 \\
\hline $\begin{array}{c}\mathrm{k}\left(70^{\circ} \mathrm{C}\right) \\
{[1 / \mathrm{mol} . \mathrm{h}]}\end{array}$ & 0.093 & 0.096 & 0.093 \\
\hline $\begin{array}{c}\mathrm{k}\left(75^{\circ} \mathrm{C}\right) \\
{[1 / \mathrm{mol} . \mathrm{h}]}\end{array}$ & 0.140 & 0.147 & 0.136 \\
\hline
\end{tabular}

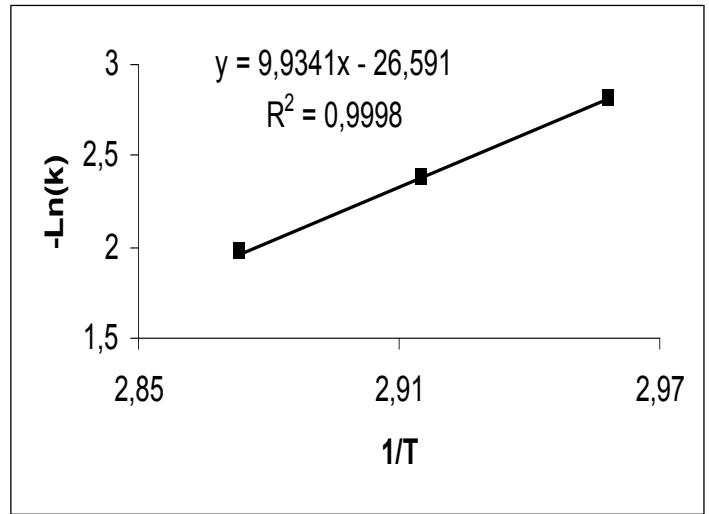

Fig.7 Trendline of the experimental values found for the kinetic data

Arrhenius' law shows that a plot of $-\mathrm{Ln}(\mathrm{k})=\mathrm{f}(1 / \mathrm{T})$ allows the chemical constants to be determined (Figure 7)

Evaluation of the constants

- The activation energy:
$\mathrm{Ea}=82500 \pm 1000[\mathrm{~J} / \mathrm{mol}]$

- The pre-exponential factor

$\mathrm{k}^{\circ}=3.5 \cdot 10^{11} \pm 0,5^{*} 10^{11}[1 / \mathrm{mol} . \mathrm{h}]$

with $\mathrm{k}=\mathrm{k}^{\circ} \exp$ 县 $\mathrm{Ea}$ 貝

\section{Optimisation of the reaction:}

\subsection{Theoretical optimization}

The optimisation described in Section 1 is performed on the esterification reaction. The reaction is simulated in the isothermal mode. The temperature of the reaction mass is $70^{\circ} \mathrm{C}$. The maximum temperature allowed $\left(\mathrm{T}_{\max }\right)$ is set to $132^{\circ} \mathrm{C}$, the lower boiling point of the products.

With such a slow reaction, the safety constraint $\mathrm{q}_{\mathrm{rx}}$ $<\mathrm{q}_{\mathrm{ex}}$ cannot be reached under the chosen experimental conditions.

The optimal input is a non-linear function. This is difficult to achieve in the production. Therefore, it is approximated by successive segments with constant feed rates (see Figure 8).

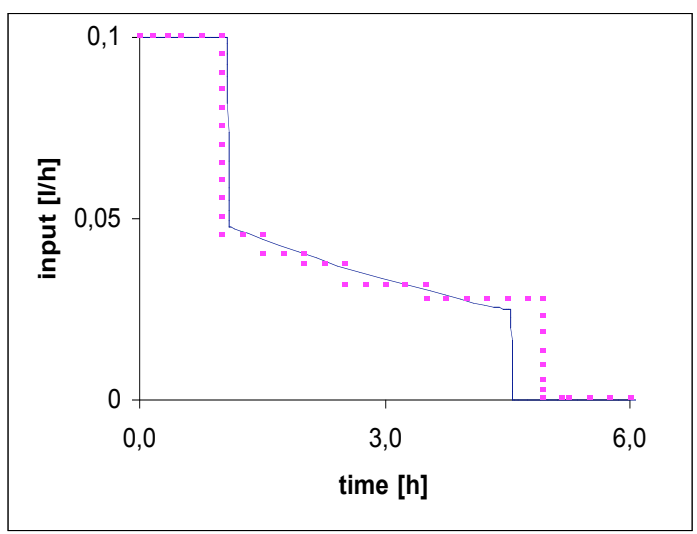

Fig.8 Evolution of the optimal theoretical (solid line) and experimental (dash line) input

With the linearised profiles for the input, the constraint is closely fulfilled. Indeed:

$$
\operatorname{MTSR}=\operatorname{Max}\left(\mathrm{T}_{\mathrm{cf}}\right)=132,2{ }^{\circ} \mathrm{C}
$$

However, since in practice, some errors may occur, especially on the determination of the reaction rate and on the control of the feed rate, some simulations with "wrong values" are realised. It appears that:

If the "real" reaction rate constant is $5 \%$ lower than expected, the MTSR will violate the constraint and reach $136^{\circ} \mathrm{C}$.

If the addition is controlled in a bad way, the MTSR will be significantly affected. For the linearised input, an overshoot of 5\% in the first step results in an increase of the MTSR to $135,5^{\circ} \mathrm{C}$. 
In order to take account of possible errors, the $T_{\max }$ used for the optimisation is not $132^{\circ} \mathrm{C}$, but $127^{\circ} \mathrm{C}$. It results in an according safety margin. For this maximum allowed reachable temperature in case of a cooling failure, the optimisation procedure described in Section 1 is performed and then tested on the esterification reaction. The reaction is run in the isothermal mode in the $\mathrm{RC} 1$ calorimeter equipped with an infra-red probe. The temperature of the reaction mass is $70^{\circ} \mathrm{C}$.

\subsection{Spectroscopic results}

Since the reaction is slow and only weakly exothermic, the process is controlled by the constraint (9). In case of a cooling failure, the system must remain below the maximum temperature $\left(\mathrm{T}_{\max }\right)$. The graph depicted in Figure 9 gives the temperature under cooling failure as a function of time.

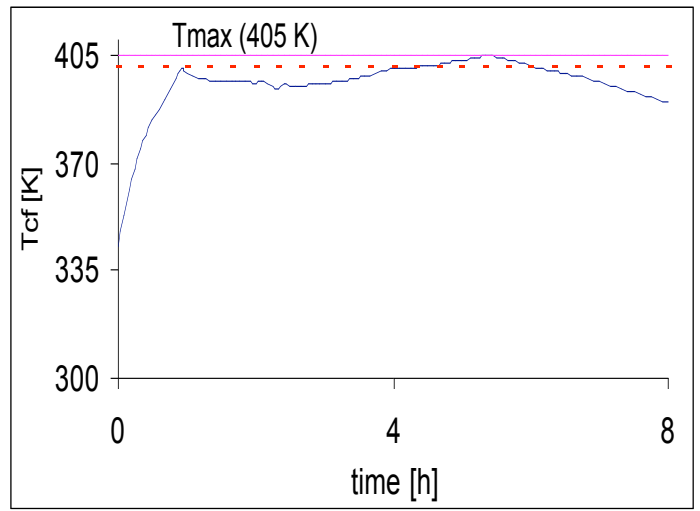

Fig.9 Evolution of the experimental $\mathrm{T}_{\mathrm{cf}}$ (solid line) versus the real (...) and the used for optimisation (--) maximum temperature (dash line).

The constraint is respected at any instant. The system rides on the safety constraint showing that the optimisation is well performed. The final conversion is at its maximum.

Concerning this optimization, two interesting comparisons can be carried out:

- In comparison to the semi-batch, the batch reactor gives a higher final conversion. However, it presents a definitely higher risk in case of malfunction of the cooling system.

- In production, often, in order to respect the safety constraints, the input profile is constant. Here, the "optimized input constant rate" is 0,03 $1 / \mathrm{h}$. With such a value, the MTSR is $132^{\circ} \mathrm{C}$.

The Figure 10 compares the time necessary to reach $60 \%$ of conversion for the experimental and simulated reaction modes (batch, semi-batch constant input, semi-batch optimized input).

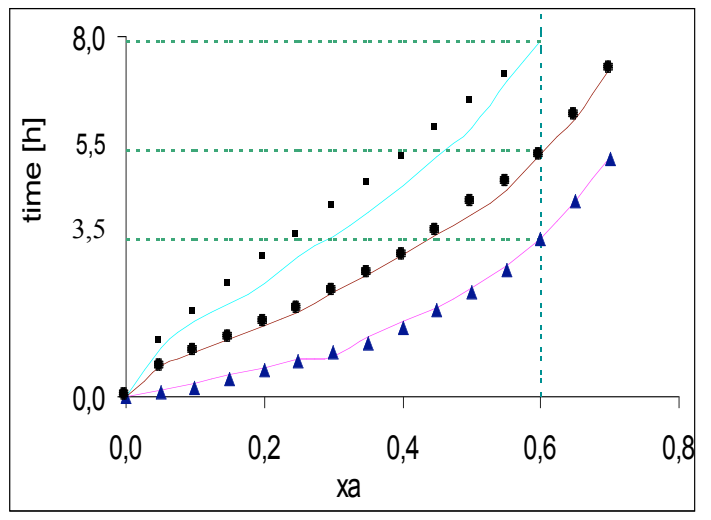

Fig. 10 Evolution of the time needed for an imposed conversion for the experimental (solid line) and simulated (dash line) reaction system: the batch ( $\bullet$ ), the constant ( $\square)$ and optimized ( input for the semi-batch.

Even if the batch process presents a faster production, semi-batch operation has to be preferred with regard to the safety aspects. The variable and optimized feed rate allows to achieve a given conversion in a significantly shorter time than with the constant input. Consequently the variable feed rate represents an economic improvement. The productivity is increased by more than $30 \%$ approaching the productivity of a batch reactor.

\subsection{Calorimetric results}

The calorimetric results are more difficult to work with, because they are not specific to the reaction. As it is for calorimetry in general, they represent the sum of all thermal phenomena occurring during the reaction. In our case there are at least two different contributions to the heat balance. One is linked to the chemical reaction we want to measure, the other is connected to the heat of mixing of the feed with the reaction mass. The heat evolution can be described by the equation (18).

$$
\mathrm{q}_{\mathrm{rx}}=\mathrm{UA}\left(\mathrm{T}_{\mathrm{r}} \square \mathrm{T}_{\mathrm{j}}\right)+\mathrm{mc}_{\mathrm{p}} \frac{\mathrm{dT}_{\mathrm{r}}}{\mathrm{dt}}+\mathrm{q}_{\text {mix }}+\mathrm{q}_{\mathrm{dos}}
$$

where $U$ is the global heat transfer coefficient, A the exchanged area, $T_{j}$ is the jacket temperature, $m$ the mass of the reaction system, $\mathrm{q}_{\text {mix }}$ the enthalpy of mixing and $\mathrm{q}_{\mathrm{dos}}$ the thermal effect due to the temperature difference between the feed and the reaction mass (sensible heat).

$$
\mathrm{q}_{\text {mix }}=\frac{\square \mathrm{H}_{\text {mix }} \mathrm{u}}{\mathrm{V}_{\text {mol }}}
$$

where $\square \square_{\text {mix }}$ is the mixing energy, $u$ the input and $\mathrm{V}_{\text {mol }}$, the molar volume of the 2-butanol.

$$
\mathrm{q}_{\mathrm{dos}}=\mathrm{u} \square \mathrm{c}_{\mathrm{p}}\left(\mathrm{T}_{\mathrm{r}} \square \mathrm{T}_{\mathrm{dos}}\right)
$$

where $c_{p}$ is the heat capacity, $\square$ the density and $\mathrm{T}_{\mathrm{dos}}$ the temperature of the 2-butanol added.

Since both effects are lumped, the reaction rate or the conversion can only be determined after deconvolution. This requires an other experiment 
which allows to determine the heat of mixing independently of the reaction. This can be done for example by mixing both reactants at a lower temperature where the reaction is very slow compared to the rate of mixing. In our case we can also use the spectroscopic measurement to correct the thermal measurement.

There is an additional difficulty to overcome during calorimetric measurements. This is the variation of heat losses which can cause an additional perturbation. For our specific case, heat losses are mainly due to the evaporation of the reaction mass. As proposed by Lerena (1998) they can be assumed to be proportional to the vapour pressure of the reaction mass:

$$
\mathrm{q}_{\text {loss }} \square \mathrm{x}_{\mathrm{i}} \mathrm{P}_{\mathrm{i}}
$$

The vapour pressure can be calculated by the Clausius-Clapeyron equation (eq. 22). By applying these corrections, the measured heat release rate curve is in good agreement with the calculated curve from the kinetic evaluation of the calorimetric and spectroscopic experiments (fig11).

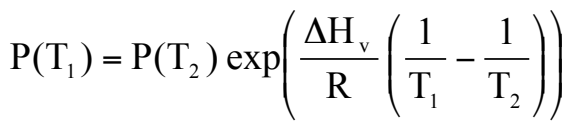

where $\square H_{v}$ is the heat of vaporisation.

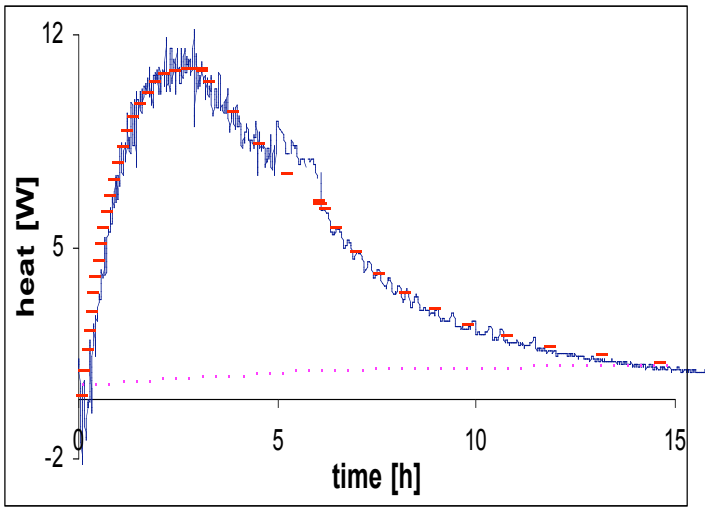

Fig. 11 Evolution of the experimental (solid line) and theorical (---) chemical heat produced versus the base line ( $(\cdots)$

With this corrected heat evolution, it is now possible to calculate the thermal conversion and to correlate it with the chemical conversion required to calculate the optimal feed rate. The figure 12 shows the evolution of the constraint calculated.

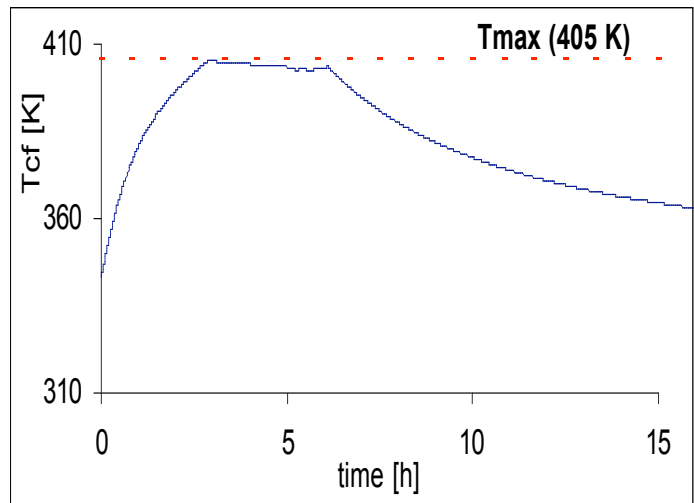

Fig.12 Evolution of the experimental $\mathrm{T}_{\mathrm{cf}}$ versus the real maximum temperature.

The system rides on the constraint without violating it. The optimisation is well performed.

The results obtained by the calorimetry method are nearly the same than those obtained by the spectroscopic method.

\section{Conclusion}

In this work, an experimental study of an off-line optimisation for an isothermal semi batch reactor has been presented. In this kind of optimization, the main difficulty is in the identification of the kinetic model and in the determination of its parameters. For this work, an approach using coupled spectroscopic and calorimetric measurements presents a significant advantage. These methods complete each other in the way that the weakness of the calorimetry in the selectivity is compensated by the selectivity of the spectroscopic measurements. On the other hand, calorimetry, since it is a differential method, delivers a signal which can be directly used for the control of the feed. The spectroscopic measurement, if properly calibrated, also delivers the exact final conversion which is essential for the determination of the reaction kinetic as by integral methods. This is a great help in definition of the base line at the end of the calorimetric experiment. This is especially critical in the slow example reaction.

Even if the calorimetric measurement cannot be used as a standalone technique for the identification of the kinetic model, it is more sensitive to deviations in the feed rate from the optimum profile than an integral method would be. Thus the integral approach provided by the spectroscopic measurement is preferred for the identification of the kinetic model. But for an on-line control of the reaction, the differential approach provided by the calorimetric measurement is preferred. Both methods complete each other in a very interesting way.

Numerical Values of experimental conditions

\begin{tabular}{|c|c|c|c|}
\hline Symbol & Description & Value & Unit \\
\hline$\square \mathrm{Hr}$ & Reaction enthalpy & -60000 & {$[\mathrm{~J} / \mathrm{mol}]$} \\
\hline$\square$ & Density & 900 & {$\left[\mathrm{~kg} / \mathrm{m}^{3}\right]$} \\
\hline$c_{\mathrm{p}}$ & Heat capacity & 2000 & {$[\mathrm{~J} / \mathrm{kg} . \mathrm{K}]$} \\
\hline
\end{tabular}




\begin{tabular}{|c|c|c|c|}
\hline $\mathrm{U}$ & Heat transfer coefficient & 190 & {$\left[\mathrm{~W} / \mathrm{m}^{2} . \mathrm{K}\right]$} \\
\hline $\mathrm{d}_{\mathrm{r}}$ & Radius of the reactor & 0,076 & {$[\mathrm{~m}]$} \\
\hline $\mathrm{k}^{\circ}$ & Pre-exponential factor & $3.510^{11}$ & {$[\mathrm{l} / \mathrm{mol} . \mathrm{h}]$} \\
\hline $\mathrm{Ea}$ & Activation energy & 82500 & {$[\mathrm{~J} / \mathrm{mol}]$} \\
\hline $\mathrm{N}_{\mathrm{A}, 0}$ & Number of mole of A & 2,5 & {$[\mathrm{~mol}]$} \\
\hline $\mathrm{N}_{\mathrm{B}, 0}$ & Number of mole of $\mathrm{B}$ & 2,5 & {$[\mathrm{~mol}]$} \\
\hline $\mathrm{V}_{\mathrm{A}, 0}$ & Volume of A & 0,32 & {$[1]$} \\
\hline $\mathrm{V}_{\mathrm{B}, 0}$ & Volume of B & 0,23 & {$[\mathrm{l}]$} \\
\hline $\mathrm{V}_{\operatorname{mol}}$ & Molar Volume of B & $9,1710^{-5}$ & {$\left[\mathrm{~m}^{3} / \mathrm{mol}\right]$} \\
\hline $\mathrm{T}_{\max }$ & Safety temperature & 405 & {$[\mathrm{~K}]$} \\
\hline $\mathrm{T}_{\mathrm{dos}}$ & Dosing temperature & 298 & {$[\mathrm{~K}]$} \\
\hline $\mathrm{T}_{\mathrm{c}}$ & $\begin{array}{c}\text { Minimal temperature of } \\
\text { the cooling liquid }\end{array}$ & 300 & {$[\mathrm{~K}]$} \\
\hline $\mathrm{u}_{\min }$ & Minimum flux & 0 & {$\left[\mathrm{~m}^{3} / \mathrm{s}\right]$} \\
\hline $\mathrm{u}_{\max }$ & Maximum flux & $2,77 \mathrm{E}-8$ & {$\left[\mathrm{~m}^{3} / \mathrm{s}\right]$} \\
\hline
\end{tabular}

\section{Acknowledgement}

This work is a part of the $\mathrm{PhD}$ thesis prepared by O. Ubrich at the E.P.F.L. with the financial support of the Corporate Heath, Safety and Environment of Novartis A.G. (Basel). Doctor Eigenmann, head of this department is especially thanked.

\section{References}

Chalmers, J., Dent, G. (1997). Industrial Analysis With Vibrational Spectroscopy. Royal Society of Chemistry Press.

Crouch, S. R., Cullen, T. F. (1998). Kinetic determinations and some kinetic aspects of analytical chemistry. Anal. Chem. 70, 53R-106R.

C80 (1996) Setaram, User Manual.

Drago, R. S. (1977). Physical Methods in Chemistry. W. B. Saunders Company Press.

Hesse, M., Meier, H., Zeeh, B. (1997). Spectroscopic Methods in Organic Chemistry. Thieme Press.

Holzwarth, A. R. (1996). Adv. Photosynth. 3, 7592.

Hugo, P., Steinbach, J., Stoessel, F. (1988). Calculation of the maximum temperature in stirred tank reactors in case of a breakdown of cooling. Chem. Eng. Sci. Vol.43,8, 2147-2152.

Lerena, P., Wehner, W., Weber, H., Stoessel, F. (1996). Assessment of hazards linked to accumulation in semi-batch reactor. Thermochimica Acta. 289, 127-142.

Lerena, P. (1998). Calorimetry training course. Novartis Services A.G..

Leonhardt, J., Hugo, P. (1997). Comparison of thermokinetic data obtained by isothermal, isoperibolic, adiabatic and temperature programmed measurements. J. Thermal Analysis, 49, 15351551.

Maria, G., Heinzle, E. (1998). Kinetic system identification by using short-cut techniques in early safety assessment of chemical process. J. Loss Prev. Process Ind., 11 187-206.

RC1 (1995) Mettler Toledo, Operating Instruction.

Regenass, W. (1997). The development of stirredtank heat flow calorimetry as a tool for process optimisation and process safety. Chimia 51 189200.

Rogers, R. (1997). Hazards from Chemical Reactions and Flammable Materials in Batch Reactor Operations. In P. N. Sharratt (Ed.), Handbook of batch process design. London: Blackie Academic and Professional.

Scientist 2.0 (1995). MicroMath Inc.

Snee, T.J., Bassani, C., Ligthart, J.A.M. (1993). Determination of the thermokinetic parameters of an exothermic reaction using isothermal, adiabatic and temperature-programmed calorimetry in conjunction with spectrophotometry. J. Loss Prev. Process Ind. 6, 87-94.

Strozzi, F., Zaldìvar, J.M., Westerterp, K.R. (1997). Runaway prevention in chemical reactors using chaos theory techniques. Joint research centre, Report EUR 17696 EN.

Ubrich, O., Srinivasan, B., Stoessel, F., Bonvin, D. (1999). Optimisation of a semi-batch reaction system under safety constraints. $5^{\text {th }}$ European Control Conference. 